\title{
Special Issue on "Applied Biocatalysis in Europe: A Sustainable Tool for Improving Life Quality"
}

\author{
Andrés R. Alcántara ${ }^{1, *(D)}$ and Francisco J. Plou $2, *$ (D) \\ 1 Department of Chemistry in Pharmaceutical Sciences, Pharmacy Faculty, Complutense University of \\ Madrid (UCM), Ciudad Universitaria, Plaza de Ramon y Cajal, s/n., 28040 Madrid, Spain \\ 2 Instituto de Catálisis y Petroleoquímica, CSIC, Marie Curie 2, 28049 Madrid, Spain \\ * Correspondence: andalcan@ucm.es (A.R.A.); fplou@icp.csic.es (F.J.P.)
}

check for updates

Citation: Alcántara, A.R.; Plou, F.J. Special Issue on "Applied Biocatalysis in Europe: A Sustainable Tool for Improving Life Quality". Catalysts 2021, 11, 339. https:// doi.org/10.3390/catal11030339

Received: 1 March 2021

Accepted: 3 March 2021

Published: 6 March 2021

Publisher's Note: MDPI stays neutral with regard to jurisdictional claims in published maps and institutional affiliations.

Copyright: (c) 2021 by the authors. Licensee MDPI, Basel, Switzerland. This article is an open access article distributed under the terms and conditions of the Creative Commons Attribution (CC BY) license (https:/ / creativecommons.org/licenses/by/ $4.0 /)$.
Applied biocatalysis, i.e., the use of enzymes and whole-cell systems in manufacturing processes for synthetic purposes, has been experiencing a clear boom in recent years, which has led to the start of the so-called "fourth wave". In fact, the latest advances in bioinformatics, system biology, process intensification, and in particular, enzyme-directed evolution (encouraged by the 2018 Nobel Prize awarded to F. Arnold) are widening the range of the efficacy of biocatalysts and accelerating the rate at which new enzymes are becoming available, even for activities not previously discovered.

Biocatalysis is the preferred alternative compared with other methodologies of traditional chemistry (based on protection/deprotection steps of functional groups, resulting in multi-step processes with a low overall yield), due to the excellent regio-, chemo- and stereo-specificity of enzymes, as well as to the mild conditions required. Biocatalytic processes are mostly environmentally friendly and generate fewer amounts of waste compared with conventional organic synthesis.

Biocatalysis is a cost-effective and sustainable technology that fulfils most of the principles of green chemistry. This tool has been applied for the manufacture of a wide range of compounds for different areas, including the food, chemical, pharmaceutical and cosmetic industries. Figure 1 represents some of the most important substances currently synthesized with the use of enzymes.

Nine contributions dealing with different aspects of applied biocatalysis are gathered in this Special Issue. The main topics are summarized herein.

Zaccone et al. have reported on a transesterification strategy to synthesize the bioactive compound (R)-3-hydroxybutyl-( $R$ )-3-hydroxybutyrate [1]. The reaction exploited the stereoselectivity of Candida antarctica lipase B, which was very efficient for the kinetic resolution of the racemate.

The issue of the production of omega- 3 ethyl esters was investigated and thoroughly discussed by Aguilera-Oviedo et al. [2], who employed enzymes (Candida antarctica lipase B) or resting cells (Aspergillus flavus and Rhizopus oryzae) as biocatalysts.

Estévez-Gay et al. accomplished the computational study of halohydrin dehalogenases $(\mathrm{HHDH})$, a family of enzymes that exhibit a promiscuous epoxide-ring opening activity [3] Coupling the analysis of conformational landscapes with calculations of tunnels and channels by CAVER software, they assessed their impact on the active site tunnels and the potential ability of HHDH to catalyze the ring opening of bulky epoxides, providing key information for HHDH engineering.

Ramos-Martín et al. accomplished the challenge of obtaining high enantioselectivity at high temperatures [4]. For such purposes, they employed a thermophilic lipase for the synthesis of both enantiomers of mandelic acid by the ethanolysis of a racemate. The best performance was obtained in imidazolium-based ionic liquids at temperatures as high as $120^{\circ} \mathrm{C}$.

Coloma et al. developed an immobilization strategy on controlled-porosity glass to increase the stability in acidic media of hydroxynitrile lyase from Arabidopsis thaliana [5]. 
The enzyme was decorated with a His-tag to improve immobilization, and the resulting biocatalysts were efficient in the selective synthesis of $(R)$-cyanohydrins in batch and continuous flow systems.

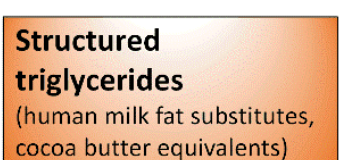

cocoa butter equivalents)

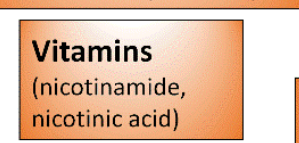

Flavors and fragances (vanillin)
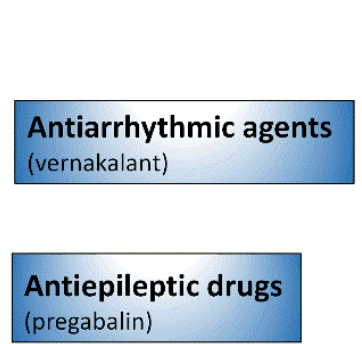

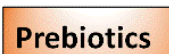

$$
\begin{aligned}
& \text { Prebiotics } \\
& \text { (FOS, GOS) }
\end{aligned}
$$

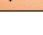

Bioactive peptides (antyhypertensive)

\section{Sweeteners}

(fructose, aspartame, isomaltulose, stevia glucosides, tagatose)

\section{Cyclodextrins}

\section{Polyphenol derivatives}

(bioethanol, biodiesel biobutanol)

Biopolymers

(polylactic acid, glucans)

\section{Commodity}

chemicals

(acrylamide. diacids)

Emolient esters

(myristyl myristate)

\section{BIOCATALYS/S}

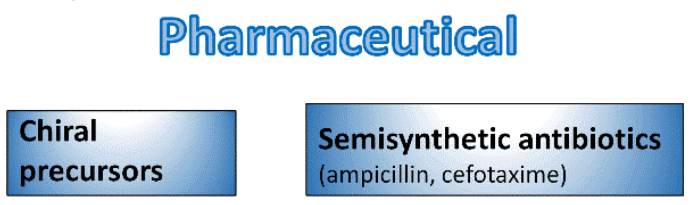

Antihyperlipidemic drugs (atorvastatin)

(ampicillin, cefotaxime)

Antitumorals

(paclitaxel)

\section{Antivirals}

(islatravir)

\section{Anti-diabetic agents (sitagliptin)}

\section{Antihypertensive agents}

(indolapril)

Figure 1. Examples of current applications of biocatalysis for the synthesis of compounds for the food, chemical, cosmetic and pharmaceutical industries. FOS: fructooligosaccharides; and GOS: galactooligosaccharides.

Arslan et al. developed a transesterification process to synthesize a group of fatty acid polyesters of great potential called estolides [6]. They used castor oil as raw material and Candida antarctica lipase A as biocatalyst. They obtained estolide trimers and tetramers and proposed multienzyme systems to control product selectivity.

Velasco-Bucheli et al. [7] studied in detail the hydrolysis of $\mathrm{N}$-acyl-homoserine lactones using two enzymes: penicillin acylase from Streptomyces lavendulae and aculeacin A acylase from Actinoplanes utahensis. They proved the involvement of both enzymes in quorum quenching (QQ) processes by Chromobacterium violaceum CV026-based bioassays and the inhibition of biofilm formation by Pseudomonas aeruginosa, which suggests the application of these enzymes as quorum quenching agents.

Cervantes et al. presented a three-stage process for the valorization of cheese whey into the functional sweetener $D$-tagatose [8]. The $\beta$-galactosidase from Bifidobacterium bifidum hydrolyzed lactose, and the glucose was selectively removed by treatment with Pichia pastoris cells, and L-arabinose isomerase US100 from Bacillus stearothermophilus isomerized $D$-galactose into $D$-tagatose.

Ntana et al. reviewed the pivotal role of Aspergillus species in the field of industrial biotechnology [9], in particular as cell factories for the efficient production of recombinant proteins, including many commercial enzymes. The authors went over the advances in the Aspergillus-specific molecular toolkit and the use of engineering strategies to increase the expression levels of recombinant fungal proteins. The strategies to overcome the limitations in the production of non-fungal proteins was also covered.

In conclusion, the editors hope that the articles included in this Special Issue of Catalysts clearly illustrate the versatility of soluble and immobilized enzymes as efficient catalysts in their different areas of application, and the potential of European research laboratories devoted to this field. We really appreciate the authors for their excellent contributions and the reviewers for their comments, which highlighted certain shortcomings 
in the manuscripts and helped improve them. We thank the staff of the editorial office of Catalysts, and in particular the formidable work done by Caroline Zhan, assistant editor.

Funding: This work was supported by grants from the Spanish Ministry of Science and Innovation (Grants PID2019-105838RB-C31 and PID2019-105337RB-C22).

Conflicts of Interest: The authors declare no conflict of interest.

\section{References}

1. Zaccone, F.; Venturi, V.; Giovannini, P.P.; Trapella, C.; Narducci, M.; Fournier, H.; Fantinati, A. An Alternative Enzymatic Route to the Ergogenic Ketone Body Ester (R)-3-Hydroxybutyl (R)-3-Hydroxybutyrate. Catalysts 2021, 11, 140. [CrossRef]

2. Aguilera-Oviedo, J.; Yara-Varón, E.; Torres, M.; Canela-Garayoa, R.; Balcells, M. Sustainable Synthesis of Omega-3 Fatty Acid Ethyl Esters from Monkfish Liver Oil. Catalysts 2021, 11, 100. [CrossRef]

3. Estévez-Gay, M.; Iglesias-Fernández, J.; Osuna, S. Conformational Landscapes of Halohydrin Dehalogenases and Their Accessible Active Site Tunnels. Catalysts 2020, 10, 1403. [CrossRef]

4. Ramos-Martín, J.; Khiari, O.; Alcántara, A.R.; Sánchez-Montero, J.M. Biocatalysis at Extreme Temperatures: Enantioselective Synthesis of both Enantiomers of Mandelic Acid by Transesterification Catalyzed by a Thermophilic Lipase in Ionic Liquids at $120^{\circ} \mathrm{C}$. Catalysts 2020, 10, 1055. [CrossRef]

5. Coloma, J.; Lugtenburg, T.; Afendi, M.; Lazzarotto, M.; Bracco, P.; Hagedoorn, P.-L.; Gardossi, L.; Hanefeld, U. Immobilization of Arabidopsis thaliana Hydroxynitrile Lyase (AtHNL) on EziG Opal. Catalysts 2020, 10, 899. [CrossRef]

6. Arslan, A.; Rancke-Madsen, A.; Brask, J. Enzymatic Synthesis of Estolides from Castor Oil. Catalysts 2020, 10, 835. [CrossRef]

7. Velasco-Bucheli, R.; Hormigo, D.; Fernández-Lucas, J.; Torres-Ayuso, P.; Alfaro-Ureña, Y.; Saborido, A.I.; Serrano-Aguirre, L.; García, J.L.; Ramón, F.; Acebal, C.; et al. Penicillin Acylase from Streptomyces lavendulae and Aculeacin A Acylase from Actinoplanes utahensis: Two Versatile Enzymes as Useful Tools for Quorum Quenching Processes. Catalysts 2020, 10, 730. [CrossRef]

8. Cervantes, F.V.; Neifar, S.; Merdzo, Z.; Viña-Gonzalez, J.; Fernandez-Arrojo, L.; Ballesteros, A.O.; Fernandez-Lobato, M.; Bejar, S.; Plou, F.J. A Three-Step Process for the Bioconversion of Whey Permeate into a Glucose-Free D-Tagatose Syrup. Catalysts 2020, 10, 647. [CrossRef]

9. Ntana, F.; Mortensen, U.H.; Sarazin, C.; Figge, R. Aspergillus: A Powerful Protein Production Platform. Catalysts 2020, 10 , 1064. [CrossRef] 